Revista de Estudios Histórico-Jurídicos

[Sección del pensamiento político]

XLII (Valparaíso, Chile, 2020)

[pp. 761-779]

\title{
EL PENSAMIENTO ROMANO EN EL DISCURSO POLITICO- JURIDICO DE JOHANNES Althusius (1563-1638). EL HUMANISMO BARROCO
}

[The Roman thought in Johannes Althusius' (1563-1638) legal-political discourse. Baroque humanism]

\author{
Patricio H. Carvajal A.* \\ Universidad de Talca, Chile
}

\section{RESUMEN}

La presente investigación estudia la traslación del pensamiento romano en el discurso político jurídico de J. Althusius. A partir de ese proceso junto con los principios de la reforma protestante calvinista y la revolución científica moderna, se genera el liberalismo. Este último sirve de base al constitucionalismo y la codificación en Europa y América.

\section{Palabras clave}

Derecho romano - reforma protestante - humanismo barroco - liberalismo - constitucionalismo - codificación.

\section{Abstract}

This article examines the rendering of the Roman thought into J. Althusius' legal-political discourse. Said process, together with the principles of the Calvinist Reformation and the Modern scientific revolution, gave rise to liberalism, which, in turn, laid the foundations for the constitutionalism and codification in Europe and the Americas.

\section{Key Words}

Roman law - Protestant Reformation - Baroque humanism - liberalism - constitutionalism - codification.

Recibido el 20 de abril de 2019 y aCEPTADo el 19 de junio de 2020

\section{INTRODUCCIÓN}

En plena controversia entre pro romanistas y anti romanistas, a comienzos del siglo XVII, en el contexto del humanismo barroco alemán, señalaba Althusius en la política que cada pueblo tiene su derecho comunitario, pero que junto con aquel derecho propio utilizado por cada comunidad, todos los pueblos europeos emplean el derecho romano ${ }^{1}$. Con estas palabras del jurista de Herborn nos aproximamos en el tema de la presente investigación. Pero antes, revisamos sumariamente

* Miembro de la Althusius-Gesellschaft. Dirección del autor: althusius57@hotmail.com

${ }^{1}$ Althusius, Politik, kap. XXI. 33 (1603, traducción alemana de Dieter Wyduckel, Berlin, Duncker \& Humblot, 2003), p. 231: "Dieses besondere Gesetz war ein anderes bei den Juden im jüdischen Gemeinwesen, bei den Römern und bei anderen Völkern und ist wiederum ein anderes heute bei den Deutschen. Gleichwohl bedienen sich die allermeisten Gemeinwesen Europas heute 
el significado del derecho romano en la cultura alemana. En efecto, desde una perspectiva diacrónica se pueden establecer los siguientes momentos históricos del derecho romano en la historia de Alemania, a saber: imperio medieval ${ }^{2}$, humanismo renacentista ${ }^{3}$, reforma protestante ${ }^{4}$, humanismo barroco, ilustración ${ }^{5}$, romanticismo ${ }^{6}$, idealismo, marxismo ${ }^{7}$, y el anti romanismo nacionalsocialista, y los romanistas germanos forzados al exilio ${ }^{8}$.

La presente investigación está concebida desde la perspectiva metodológica de la historia del pensamiento, según la propuesta de Q. Skinner ${ }^{9}$ También considera la propuesta epistémica de la Geschichtliche Grundbegriffe de la Escuela de R. Koselleck. La historia del pensamiento proporciona la contextualidad histórica y la historicidad del texto; la historia conceptual la estructura semántica del discurso ${ }^{10}$. Desde ambas perspectivas historiográficas la traslación del pensamiento romano en la obra de J. Althusius - la diacronía del derecho romano- se reformula como una lingüística específica jurídico-política que da origen al discurso jurídico del constitucionalismo y de la codificación moderna.

Joahannes Althusius pertenece a la generación de juristas formados en los principios del humanismo renacentista y de la reforma protestante. Desde esta perspectiva la obra del jurista germano constituye una síntesis del pensamiento romanista y teología reformada calvinista. Hasta ahora la Althusiusforschung no cuenta con un trabajo sobre la actividad del jurista de Herborn como romanista. Esa fue su profesión como UJD de la Universidad de Basel ${ }^{11}$, como profesor de

des römischen Rechts, das in den Digesten, im Codex in den Novellen und in den Institutionen niedergelegt ist".

${ }^{2}$ LePsIUs, Susanne, Ius Commune in der Reichspublizistik der frühen Neuzeit, en DiLCHER, Gerhard; Quaglioni, Diego (eds.), Gli inizo del diritto publico (Bologna, Il Mulino, 2011), pp. 533-562.

${ }^{3}$ CoInG, Helmut (ed.), Handbuch der Quellen und Literatur der neueren Europäische Privatrechtsgeschichte (München, Beck, 1996) Bd I; (München, Beck, 1977) Bd. II.

${ }^{4}$ STroнm, Christoph, Ethik im frühen Calvinimus. Humanistische Einflüsse, philosophische, juristische und theologische Argumentationen sowie mentalitätsgeschichtliche Aspekte am Beispiel des Calvin-Schülers Lambertus Danaeus (Berlin, de Gruyter, 1996).

${ }^{5}$ Haferkamp, Hans-Peter; Repgen, Tilman (eds.), Usus modernus pandectarum. Römisches Recht, Deutsches Recht und Naturrecht in der Frühen Neuzeit (Köln, Böhlau Verlag, 2007).

${ }^{6}$ Nilges, Yvonne, Dichterjuristen. Studien zur Poesie des Rechts vom 16. Bis 21. Jahrhundert (Würzburg, Könighauser \& Neumann, 2014).

${ }^{7}$ ERnst, Wolfgang; JAKAB, Eva (eds.), Usus Antiquus Juris Romani / Antikes Recht in lebendespraktischen Anwendung (Berlin, Springer Verlag, 2005).

${ }^{8}$ Zimmermann, Reinhard, Jurists Uprooted. German-speaking Emigré Lawyers in TwentiehCentury Britain (Oxford University Press, 2004); Mussang, Dorothee, Ernst Levy and Wolfgang Kunkel Briechwechsel 1922-1968 (Heidelberg, Verlag Winter, 2005); STOLLEIS, Michael, Recht in Unrecht. Studien zur Rechtsgeschichte des Nationalsozialismus (Frankfurt am Main, Suhrkamp, 2006).

${ }^{9}$ SkInner, Quetin, Los fundamentos del Pensamiento Político moderno (trad. Castellana. México, Editorial Fondo de Cultura Económica, 1993). Vol I. El renacimiento.

${ }^{10}$ Koselleck, Reinhardt, Begriffsgeschichten (Frankfurt am Main, Suhrkamp, 2006).

${ }^{11}$ Thieme, Hans, Die Basler Doktorthesen des Johannes Althusius, De succesione ab intestato, en Obermayer, Klaus (ed.), Festschrift für Hans Liermann zum 70. Geburtstag (1964). 
derecho romano en la Facultad de Jurisprudencia de la Escuela de Herborn ${ }^{12}$ y como síndico de la ciudad de Emden ${ }^{13}$. En todas estas actividades es el jurista romanista que actúa conforme a su conocimiento disciplinario sobre el cual construirá las bases del constitucionalismo y la codificación moderna. Con todo, los estudios de la historiografía jurídica: Gierke ${ }^{14}$, Wyduckel ${ }^{15}$, Stolleis ${ }^{16}$ destacan

${ }^{12}$ Daнм, Karl-Wilhelm, Johannes Althusius - Ein Herborner Rechtsgelehrter als Vordenker der Demokratie, en Dahm, Wilhelm; Karl; Krawietz, Werner; Wyduckel, Dieter (eds.), Politische Theorie des Johannes Althusius (Berlin Duncker \& Humblot, 1987), pp. 21-41.

${ }^{13}$ Antholz, Heinz, Johannes Althusius als Syndicus Reipublicae Embdanae, en DaHM, KarlWilhelm; Krawietz, Werner; Wyduckel, Dieter (eds.), Politische Theorie des Johannes Althusius (Berlin, Duncker \& Humblot, 1987).

${ }^{14}$ GIERKE, Otto, Johannes Althusius und die Entwicklung der naturrechtlichen Staatstheorien. Zugleich ein Beitrag zur Geschichte der Rechtssystematik (Scientia Aalen 1958). Erster Theil. Drittes Kapitel. Die Jurisprudenz des Althusius. Al resumir el significado romanista de su obra, señala Gierke, p.46: "Althusius dagegen, der in der Jurisprudentia Romana noch ähnlich wie seine Vorgänger verfahren war, machte in der Dicaeologicae mit der Eingliederung des gesammten öffentlichen Rechts in das civilistische System vollen Ernst. Da er hierbei die inzwischen in seiner Politik entwickelten Grundanschauungen überall feshielt und zur Geltungbrachte, so konnte er in der That die staatsrechtlichen Verhältnisse ohne Mühe unter die privatrechtlichen Rubriken vertheilen. Das Resultat war ein durchweg im Style des Privatrechts aufgeführtes und gleichwol die Grundlagen des öffentlichen Rechts umspannendes einheitliches Rechtsgebäude, wie es kaum jemals vorher oder nachher errichtet worden ist. Und doch waren in dieser Systematik im Grunde nur die letzten Konsequenzen der bald darauf zur Alleinherrschaft gelangten naturrechtlichen Lehre vom Socialvertrage im Voraus gezogen?'.

${ }^{15}$ Wyduckel, Dieter, Johannes Althusius, en Grossfeld, Bernhard; PotTMEyer, Ernst; Michel, Klaus; BeCKMANn, Martin (eds.), Westfälische Jurisprudenz. Beiträge zur deutschen und europäischen Rechtskultur (Münster, Waxmann, 2000). Afirma Wyduckel, p. 105: “Die Jurisprudentia Romana und die aus ihr hervorgegangene Dicaelogica machen das spezifisch juristische Werk des Althusius aus. Dieses ist weit weniger erforscht als seine politische Lehre, darum jedoch nicht weniger bedeutsam".

${ }^{16}$ StOlLeIs, Michael, Geschichte des Öffentlichen Rechts in Deutschland (München, Beck, 1988) Vol I, p.77: "Das Ius publicum der frühen Neuzeit hat sich nicht nur vom römischen Recht "emanzipiert", wie schon jetzt deutlich wird, sondern es hat paradoxerweise dort auch eine seiner Hauptwurzeln. Ulpians Formel hat es von Anfang an begleitet. Als Teilgebiet des ius civile wurde Römische Staatsrecht im Prozess der "Rezeption"-genauer: der Wellen verschiedener Rezeptionenmittransportiert und nicht anders als das dominierende ius privatum auf die mittelalterliche Rechtswirklichkeit umgesetzt. Längst vor der durch die oberitaliuenischen Universitäten vermittelten Rezeption vom 13-15.Jahrhundert bediente sich die kaiserliche Publizistik und Panegyrik der spätantiken Titulaturen, Symbole und Rechtsformeln, auf diese Weise die Rezeption und die Vorstellung eines "Kaiserrechts" vorbereitend. Das vom römischen Rechts bereitgehaltene Material, das den mittelalterlichen Glossatoren und Konsilatoren als normative Grundlage diente. Reichte von den absolutistischen Paömien (quod principi placuit legis habet vigorem; princeps legibus solutus; princeps lex animate; de principis potestate disputare, instar est sacrilegii) und vom Herrscherlob (dominus mundi, caput orbis, pater omnium, persona publica) bis zum Recht der Sätzen des Erbrechts konnte die Sonderrolle der Fürstentestamente und Hausgesetze, die Vererblichkeit und Nichtvererbbarkeit der Hersschaftssymbole abgeleitet warden. Die patria potestas bot die Anologie zur fürstlichen Herrschaft. Die Territorialgewalten stützen sich auf ihre Stellung als praesides provinciae cum mero et mixto imperio sowie auf die römische Definition des Wortes territorium (D.50.16.239.8). Kaiserliche und fürstliche Regalien wurden den Libri feudorum (F2.56) entnommen, die Lehre von den adeligen Stammgütern enstammte dem römischen Fideikommissrecht. Mit anderen Worten: das römische Recht war flexible und dank seiner Interpreten aufnahmefähig genung für veränderte 
algunos aspectos de la contribución de Althusius como romanista. Sin embargo, ha sido la historiografía del pensamiento político, concretamente los trabajos de C. J. Friedrich, la que ha contribuido mayormente en la investigación de las fuentes romanistas de la Política althusiana. En efecto, Friedrich elaboró una detallada relación de las fuentes romanístas de la Politica, la cual debía formar parte de la edición crítica planificada del texto althusiano. Pero razones económicas, según refiere Friedrich, hicieron prescindir de esa parte de la investigación. Con todo, Friedrich volvió sobre el tema en una de sus últimas publicaciones, señalando la importancia del derecho romano en la Politica de Althusius ${ }^{17}$. La Althusiusforschung ha experimentado avances importantes, especialmente las investigaciones sobre la Politica. En efecto, en el curso de estos años se publican traducciones y ediciones críticas en español ${ }^{18}$, inglés ${ }^{19}$, alemán ${ }^{20}$ e italiano ${ }^{21}$.

Ahora bien, la relación reforma protestante-liberalismo es genética, como será la relación liberalismo-constitucionalismo-codificación. La reforma dio origen a la filosofía liberal moderna ${ }^{22}$. La crítica generada por la reforma al discurso católico medieval, no sólo se limitó a los aspectos teológicos, jurídicos y canónicos, como crítica humanista, sino también sobre el papel del hombre en la creación, lo cual dio origen al debate sobre la libertad en la filosofía moderna. Según Skinner este debate sobre la libertad se genera en la filosofía estoica (Séneca, Cicerón) ${ }^{23}$. Otro tanto cabe decir sobre la teología de San Pablo y los escritos de San Agustín en cuanto a una teoría de la libertad cristiana. Así, la teología paulina se transformó en una teología de la libertad (Theologie der Freiheit) cuyo hilo conductor cruza el pensamiento cristiano desde las comunidades de la Iglesia primitiva católica hasta

Verfassungsverhältnisse, es bestimmte aber vor allem die Denkweise des neuzeitlichen Juristenstandes, der sich nun, in der Krise der Reichverfassungs zwischen 1580 und 1618 auf ein neues Terrain zu begeben hatte. Die logischen Verknüpfung und Bildung von Sachzusammenhängen auf das positive Reichs- und Territorialverfassungsrecht war das zentrale Erbstück der Rezeption für das öffentlichen Rechts".

${ }^{17}$ FrIEDRICH, Carl Joachim, Johannes Althusius und sein Werk im Rahmen der Entwicklung der Theorie von der Politik (Berlin, Duncker \& Humblot, 1975). Sostiene Friedrich, p. 55: “Viel klarer sagen sie uns etwas über seine Schulden gegenüber dem Römischen Recht. Sein Werk De arte Jurisprudentiae Romanae zeigt uns nicht nur, dass Althusius gründlich mit dem Römischen Recht vertraut war, sondern auch, dass er ihm beträchtliche Bedeutung zuschrieb. Diese Schlussfolgerung wird durch eine systematische Analyse der Politica verdeutlicht. Althusius nimmt gleichmässig auf Stellen aus dem ganzen Corpus Juris Bezug; am häufgsten, wie zu erwarten, aud die Digesten und den Kodex. Wie bereits erwähnt, entgeht Althusius nicht dem traditionellen Hang, Sätze aus dem Römischen Recht zu brauchen mit der Absicht Meinungen zur erhärten, bei denen es sich um Situationen handelt, zu denen diese Sätze aus dem Römischen Recht gar nicht passen".

${ }^{18}$ Altusio, Juan, Politica. Metódicamente concebida e ilustrada con ejemplos sagrados y profanos (trad. Primitivo Mariño, Madrid, Centro de Estudios Constitucionales, 1990).

${ }^{19}$ Althusius, Johannes, Politic (Indianapolis, transl. Frederick S. Carney, 1995).

${ }^{20}$ Althusius, Johannes, Politik (Berlin, Dieter Wyduckel, Duncker \& Humblot).

${ }^{21}$ Althusius, Johannes, La Politica elaborata orgánicamente con método, e illustrata con esempli sacrae e profani (ed. Corrado Malandrino, Torino, Claudiana, 2009), 2 vols.

${ }^{22}$ RaWLS, John, Liberalismo político (1993, traducción castellana México, Fondo de Cultura Económica, 1996); MANENT, Pierre, An intelectual History of Liberalism (1987, traducción inglesa New Yersey, Princeton University Press, 1995).

${ }^{23}$ SKINNER, Quentin, Liberty before liberalism (Oxford University Press, 1998). 
la Iglesia evangélica del presente: San Pablo, San Agustín, Luther, Calvin, Barth, Moltmann ${ }^{24}$. El liberalismo significó además una postura historiográfica crítica del absolutismo y una búsqueda de los fundamentos de la constitución histórica de los reinos europeos, impugnando así las pretensiones de la teoría absolutista. De este modo se inaugura el constitucionalismo moderno y la historia constitucional como una crítica al sistema absolutista. Este proceso se implementa con la experiencia constitucional republicana de la antigüedad clásica: república, romana, república griega, república hebrea. Estos tres paradigmas constitucionales republicanos están presentes en la Politica de Althusius. Al referirse a esta herencia cultural europea fundada en el pensamiento clásico y sus tres discursos, la jurista alemana Jutta Limbach señala que son "Die kulturellen Werte Europas"25.

\section{El HUMANISMO JURÍDICO BARROCO. EL DERECHO ROMANO MODERNO COMO UNIDAD PUBLICISTICA-PRIVATÍSTICA}

De acuerdo con la investigación historiográfica general y la historiografía jurídica particular, es posible distinguir tres etapas en el humanismo moderno, a saber: humanismo renacentista (s. XV - s. XVI), humanismo barroco (s. XVI - s. XVII), y humanismo ilustrado (s. XVIII).

El humanismo jurídico renacentista ha sido estudiado en detalle por la historiografía jurídica: G. Kisch ${ }^{26}$, E. Troje $\mathrm{e}^{27}$, A. Mazacane ${ }^{28}$, Guzmán ${ }^{29}$ y, últimamente, Strohm ${ }^{30}$. Sin embargo, hasta ahora no existe-que sepamos- una monografía sobre el humanismo jurídico barroco. Resulta necesario un estudio sobre este último, pues las diferencias entre ambos humanismos son significativas: epistemológicas, metodológicas, didácticas, y temáticas. En una palabra, el humanismo jurídico barroco está inserto en el contexto cultural de la llamada revolución científica moderna ${ }^{31}$. En este punto surge un problema de periodificación. En efecto, ya señalamos que el barroco corresponde a la cultura europea del siglo XVII. En este contexto la revolución científica tiene una periodificación muy concreta basada en la astronomía y la física, a saber: el discurso de N. Copérnico (1543) y el discurso de I. Newton (1687). En el caso concreto del humanismo jurídico barroco

${ }^{24}$ SCHOCKENDORFF, Eberhard, Theologie der Freiheit (Herder Verlag, 2007).

${ }^{25}$ Limbach, Jutta, Die kulturellen Werte Europas, en Eckert-Das Bulletin, 12 (Winter, 2012), pp. 12-17.

${ }^{26} \mathrm{KISCH}$, Guido, Gestalten und Probleme des Humanismus und Jurisprudenz. Neue Studien und Texte (Berlin, de Gruyter, 1969).

${ }^{27}$ Troje, Hans, Arbeitshypothesen zum Thema "Humanistische Jurisprudenz", en Tijdschrift voor Rechtsgeschiedenis 38 (1970), pp. 519-563.

${ }^{28}$ MazZaCANE, Aldo, Szienza, lógica e ideología nella giuresprudenza tedesca del secolo XVI (Mailand, 1971).

${ }^{29}$ GuZMÁn, Alejandro, La fijación del derecho (Valparaíso, Ediciones Universitarias de Valparaíso, 1977).

${ }^{30}$ Stronm, Christoph (ed.), Späthumanismus und Reformierte Konfession. Theologie, Jurisprudenz und Philososphie in Heidelberg in der Wende zum 17. Jahrhundert (Heidelberg, 2006).

${ }^{31}$ KuHN, Thomas, La estructura de las revoluciones cientificas (1962, traducción castellana, Fondo de Cultura Económica, Santiago, segunda reimpresión, 1996). 
podemos señalar que su inicio se encuentra en el momento de la publicación del discurso de J. Bodin (1576). Bodin establece el primer paradigma de la ciencia jurídica moderna con las teorías de la soberanía y de los derechos de la majestad. Toda la historia del derecho público moderno y contemporáneo, que en categorías historiográficas actuales llamamos historia global, se remite a la controversia entre escuelas pro soberanía y escuelas anti soberanía. A modo de ejemplo, señalamos que el capítulo más importante de esta controversia en el siglo XX se dio entre H. Kelsen y C. Schmitt ${ }^{32}$.

Los tres precursores de la escuela humanista barroca jurídica europea nacen en el siglo XVI: Bodin, Grégoire, Althusius, lo cual nos permite sostener como criterio de periodificación el año de nacimiento de dichos juristas y considerar así un contexto generacional. En Alemania el humanismo jurídico barroco comienza con la obra de Althusius (1586) y termina con la obra de S. Stryk (1692). Cabe señalar además que en Alemania la revolución científica en el ámbito de la ciencia jurídica, que desarrollará los discursos del constitucionalismo, codificación, derecho natural y derecho internacional, se extiende desde la publicación de la obra de Althusius hasta la publicación de la obra de S. Pufendorf ${ }^{33}$. Ahora bien, en el humanismo barroco alemán destacan las escuelas jurídicas de Helmsted $2006^{34}$ y Herbon ${ }^{35}$, y otras facultades de derecho público alemanas del siglo XVII ${ }^{36}$. Se podría sostener de un modo preliminar que los escritos de Althusius constituyen el canon del derecho romano del humanismo barroco. El jurista de Herborn tuvo presente tres modelos romanista, a saber: el pensamiento romanista de la Antigüedad clásica, el modelo medieval de los comentaristas -Baldo, Bártolo, Marsilio-, y el paradigma moderno de los juristas franceses J. Bodin, P. Grégoire, y el alemán H. Vultejus. Un estudio comprado de la obra de estos tres juristas podría mostrar la simbiosis -para emplear el término althusiano- entre derecho romano privado y derecho romano público, y ciencia política. En el caso de la escuela de Helmsted, el más destacado romanista fue el filósofo luterano H. Arnisaeus ${ }^{37}$. Este autor, fundador de la teoría político-jurídica absolutista alemana, realiza la traslación de la teoría bodineana de la soberanía a la cultura alemana. Pero avanza aún un paso más en

${ }^{32}$ Carvajal, Patricio, La crisis del Estado moderno. La Staatslehre europea de Martin Luther a Petra Kelly (Valparaíso, Universidad de Playa Ancha, 2009). Cap. VII. La Staatslehre de Weimar y del Tercer Reich: Hans Kelsen vs. Carl Schmitt. Geopolitica de la paz y de la guerra, pp. 211-229.

${ }^{33}$ Carvajal, Patricio; Pérez, Fernando, La revolución cientifica moderna y su impacto en el pensamiento politico-jurídico alemán del siglo XVII. Johannes Althusius (1563-1638) y Samuel Pufendorf (1634-1694), en Revista de Estudios Politicos, 180 (Madrid, 2018), pp.105-130.

${ }^{34}$ Carvajal, Patricio H, La "Staatslehre" de H. Arnisaeus (1575-1636) y la "Schule von Helmstedt". Un análisis en conmemoración de los 400 años de la "Política" (1606-2006), en REHJ., 28 (2006), pp. 551-576.

${ }^{35}$ Carvajal, Patricio H, La "Staatslehre" de Johannes Althusius (1557-1638) y la Escuela de Jurisprudencia de Herborn, en REHJ., 36 (2014), pp. 413-436.

${ }^{36}$ STOLLEIS, Michael, Geschichte de öffentliches Recht in Deutschland (München, Beck, 1988), I.

${ }^{37}$ Dreitzel, Horst, Protestantischer Aristotelismus und Absoluter Staat. Die "Politica" des Henning Arnisaeus (ca. 1575-1636) (Wiesbaden, Franz Steiner Verlag, 1970). 
la recepción de Bodin, y formula una de las primeras y más completas teoría de la legislación pública absolutista: los iura majestatis ${ }^{38}$.

A comienzos del siglo XVII Althusius y Arnisaeus sostienen la primera controversia en el Constitucionalismo alemán moderno. La controversia AlthusiusArnisaeus fue una disputa esencialmente romanista, siendo la postura de Althusius constitucional republicana, y la de Arnisaeus constitucional imperial. En Alemania durante el siglo XVII se aprecian tres tendencias, a saber: una primera, romanista absolutista (Arnisaeus); una segunda, romanista republicana (Althusius), $y$, finalmente, una tercera, anti romanista (Conring). Con la reforma protestante se inicia una nueva etapa en el derecho en Alemania: ius publicum omperii romano-germanici ${ }^{39}$. Al provocar la reforma un cambio en el estatuto jurídico del imperio germano, la institucionalidad que surge a partir del siglo XVI implicaba la formulación de un discurso histórico-constitucional y jurídico público que lo separe del derecho medieval sobre el cual se fundaban las monarquías europeas y el imperio medieval. Pero el cambio principal se dio en el ámbito de la Constitución imperial ${ }^{40}$. Se plantea aquí un tema de continuidad-ruptura tanto en el ámbito del pensamiento jurídico como de la Constitución del imperio. La controversia Althusius-Arnisaeus sentó las bases del derecho público del imperio romano germánico de la nación alemana, y posibilitó a la vez el desarrollo de la ciencia histórico jurídica e histórico constitucional a partir de los escritos de Conring y Pufendorf sobre la historia constitucional del imperio. A ello se sumarán las cátedras de derecho público y el desarrollo de una Reichspublizistik durante el siglo XVII ${ }^{41}$. A partir de este proceso según Conring el derecho público romano justineaneo no tendría más aplicación en Alemania ${ }^{42}$. Sin embargo, la postura de Conring fue más bien un desiderátum para su generación. En otras palabras, el derecho romano continuará vigente como Ratio Scripta hasta el momento de la codificación ilustrada ${ }^{43}$.

Los escritos de Pufendorf, Thomasius, y Wolff juegan un papel clave en el desarrollo del llamado derecho natural racionalista ${ }^{44}$. Por otro lado, Pufendorf

\footnotetext{
${ }^{38}$ Huesbe, Marco Antonio, Institucionalización del Estado moderno. Teoría de los "iura majestatis" (Valparaíso, Edeval, 1999).

${ }^{39}$ STOLLEIs, Michael, cit. (n. 16).

${ }^{40}$ Ibíd., pp. 154-155: “Die zentralen Fragen, um die das neue ius publicum kreiste, kamen aus drei Richtungen. Sie enstanden aus der schrittweisen Veränderung der Reichsverfassung seit 1555, aus den in der Gegenreformation verschärften Spannungen zwischen den Religionsparteien und der in den grösseren Territorien sich ausbildenden Landeshoheit. Alle drei Faktoren hingen wiederum untereinnander zusammen: Die wichtigsten Veränderungen der Reichsverfassung gingen auf die Religionsspaltung zurück, und die Landeshoheit entwickelte sic him Schatten einer insoweit in ihrer Fortentwicklung blokierten Reichsverfassung kräftig weiter".

${ }^{41}$ STOLLEIS, Michael (ed.), Staatsdenker im 17.und 18. Jahrhundert. Reichspublizistik, Politik, Naturrecht (Frankfurt am Main, Alfred Metzner Verlag, 1977).

${ }^{42}$ Conring, Hermann, De Juris publici Justinianei in Germania auctoritate (1649). Para Conring: Jus Publicum Justineaneum non obligari hodie Germaniam, en WYDUCKEl, Dieter, Ius Publicum. Grundlagen und Entwicklung des Öffentlichen Rechts und der deutschen Staatsrechtwissenschaft (Berlin, Duncker \& Humblot, 1986), p. 148.

${ }^{43}$ GuZMÁn, Alejandro, Ratio Scripta (Vitorio Klostermann, Frankfurt, 1981).

${ }^{44}$ GuZMÁn, Alejandro, La fijación del derecho. Contribución al estudio de su concepto y de sus
} 
publica en 1667 su Historia Constitucional del Imperio Germano. Con esta obra, el constitucionalismo se centra en los principios e instituciones del derecho germano, pero no prescinde en su fundamentación conceptual del derecho romano incluso de su aplicación como derecho positivo en territorio del Reich ${ }^{45}$. Además, al final de esta época aparece el tratado romanista de $S$. Stryk ${ }^{46}$. Este discurso constituye un puente entre el derecho romano del humanismo barroco y el derecho romano de la escuela histórica ${ }^{47}$

El Digesto es uno de los fundamentos del derecho moderno. En el libro primero de Justiniano se explica la división del derecho, y una metodología de análisis que considera lo público y lo privado como una unidad del orden social. Según Guzmán, en ciertas obras de la jurisprudencia romana hay elementos privatísticos como publicísticos ${ }^{48}$. Se trata pues de una cuestión tanto metodológica como epistemológica. En la Edad Media Bártolo, Baldo, Marsilio de Padua, como representantes de la escuela de los comentaristas, habían establecido dicha unidad basados en el Digesto de Justiniano. Los escritos de estos juristas serán la base de la legislación privada y de la legislación pública del Estado moderno ${ }^{49}$. El humanismo junto con redescubrir los textos de la filosofía política aristotélica y estoica, reconstruyó también la teoría política romana y la constitución republicana e imperial. Estos dos paradigmas de la historia del pensamiento político clásico son señalados por Maquiavelo como vías para la política moderna ${ }^{50}$. La república y el imperio implican un derecho romano público específico. Los tres mayores romanistas públicos de la temprana Edad Moderna: Bodinus, Tholosanus, y Althusius recepcionan el modelo constitucional republicano, los principios

clases y condiciones (Valparaíso, Ediciones Universitarias de Valparaíso, 1977). Al referirse a la escuela del derecho natural, Guzmán señala, p. 59: "Nuevos ideales de esta especie, surgidos en el renacimiento, y debidos también al nuevo planteamiento de la filosofía y de las ciencias físicas, habrían de constituirse en los basamentos del modo moderno de concebir el derecho, que es el yusracionalismo. Este nuevo modo durante todo el siglo XVII se debate en lucha con la escolástica todavía predominante; se impone en el siglo XVIII y alcanza expresión positiva a partir de la segunda mitad de este último con las grandes codificaciones de la época".

${ }^{45}$ Pufendorf, Samuel, Die Verfassung des deutschen Reiches (1667, Stuttgart, Reclam, 1985). Señala Pufendorf, p. 80: "Das heute in Deutschland geltende Recht ist gleichsam gemischt aus römischem und kanonischem Recht, aus altem Gewonheitsrecht und den einzelnen Territorial-und Stadrechten [...]", 5. Kapital. Die Beschränkungen der kaiserlichen Macht durch Kapitulationen, Gesetze und Bräuche und durch die Rechte der Stände, 13. Die legislative Gewalt.

${ }^{46}$ STRYK, Samuel, Specimen usus modernus pandectarum (1690-1692).

${ }^{47}$ Heger, Martin, Recht im "Alten Reich" - Der usus modernus, en Zeitschrift für das Juristische Studium, 2010,www.zjs-online.com

${ }^{48}$ GuZmán, Alejandro, La proyección del tratado sobre estipulaciones de los "Libri Tres Iuris Civiles" de Sabino en los "Digestas" de Juliano, las "Institutiones" de Gayo y el "Corpus Iuris, en REHJ., 30 (2008). Señala Guzmán, p. 82: "Como es sabido, en las obras jurisprudenciales romanas del tipo digesta, quaestiones, responsa, sententiae y similares, se combina el Derecho civil, el pretorio y el de ciertas normas públicas".

${ }^{49}$ SKINNER, Quentin, Los fundamentos del pensamiento político moderno. I: El renacimiento (México, Fondo de Cultura Económica, 1993).

${ }^{50}$ Machiavelli, Niccolo, Il principe (Torino, Einaudi, 1961). Cap.1. Di quante ragioni sieno e' principati, e in che modo si acquistino. P. 3: "Tutti li stati, tutti e' domini che hanno avuto e hano imperio sopra li uomini, sono stati e sono o repubbliche o principati". 
político jurídicos del derecho romano privado clásico y desde esa base normativa romana proponen un discurso político romanista público para su época. Así, la teoría de Bodin servirá de fundamento al Estado absolutista (soberanía, derecho de la majestad), aun cuando su propuesta se incline por el paradigma republicano. El caso de Grégoire es una reformulación del discurso bodineano en un conjunto de tratados extensísimos. Finalmente, Althusius recepcionará los modelos de los romanistas franceses, optando sí por el modelo constitucional republicano romano, hebreo y griego por un lado, pero aplicándolo a la realidad constitucional del imperio germano cuya singularidad constitucional marca todo el debate sobre una Constitución absolutista o Constitución republicana para Alemania en el siglo XVII ${ }^{51}$.

Ahora bien, se puede señalar que Johannes Althusius, John Locke y Baruch Spinoza son los fundadores del liberalismo político clásico europeo ${ }^{52}$. Dos aportes importantes de Althusius al constitucionalismo fueron la teoría del contrato social y la teoría de los derechos del hombre ${ }^{53}$. Sus escritos de jurisprudencia romana abarcan todas las materias del derecho privado: procesal civil, cosas, personas, familia, obligaciones, sucesión, acciones, delitos. Este orden temático-simbiosis en el lenguaje althusiano-, el jurista de Herborn lo habría recepcionado de la obra del jurista francés P. Grégoire. Este último autor escribe un extenso tratado de derecho público, en donde realiza una detallada interpretación del derecho romano privado y del derecho romano público y lo proyecta sobre la teoría política moderna que sirve de base para la construcción del Estado nacional en Francia. Todo este trabajo publicístico de Grégoire está precedido de una obra de derecho romano privado. Ahora bien, en la estructura del discurso del jurista francés hay una clara orientación hacia un constitucionalismo y codificación del derecho. Althusius ha recepcionado la metodología y algunas materias propuestas por Grégoire. Este autor, discípulo de Bodin, basado en la metodología bodineana pero también en la dialéctica ramista, formula una metodología que concibe el derecho romano como una unidad discursiva pública-privada, estableciendo así una pragmática que generará el lenguaje específico del derecho público moderno, de la ciencia política, y, en definitiva, una teoría universal del derecho ${ }^{54}$. Los principios de

${ }^{51}$ Dreitzel, Horst, Absolutismus und Ständische Verfassung in Deutschland (Mainz, Phlipp von Zabern Verlag, 1992).

${ }^{52}$ Carvajal, Patricio, en Huesbe, Marco Antonio (ed.), Arte y política del barroco (Valparaíso, Ediciones Universitarias de Valparaíso, 2000).

${ }^{53}$ Carvajal, Patricio H., Human Rights in Althusius' Political Theory: The Right of Resistance, en Carney, Frederic; Schilling, Heinz; Wyduckel, Dieter (eds.), Jurisprudenz, Politische Theorie und Politische Theologie (Berlin, Duncker \& Humblot, 2004), pp. 227-241.

${ }^{54}$ Gambino, Luigi, Il de Republica die Pierre Grégoire. Ordine político e monarchia nella Francia di fine cinquecento (Roma, Giuffrè Editore, 1978). Según Gambino: "La vastità dell erudizione e degli interessi culturali del Tolosano, unita ad una straordinaria capacità di lavoro, è documentata dalle sua opere che spaziano dal diritto sotto l'aspetto della técnica giuridica, alla filosofia del diritto, dall' epistemología alla politica. Nell' ampio arco di tempo in cui si distribuiscono e pur nella diversità dei contenuti, ese rivelano una indentità di impostazione di cui è espressione lo sforzo constante di giungere alla scoperta e alla formulazione di principi e di regole universali, nel presupposto di un'unità del sapere che è riflesso dell'unità del cosmo", p. 9. 
esta pragmática linguística jurídica se encuentran en su obra "Syntagma Iuris" 55 . Según Gambino, Grégoire perseguía un proyecto muy ambicioso: una teoría universal de la justicia ${ }^{56}$. Por otro lado, Goyard-Fabre sostiene que el racionalismo, sistematización y tendencia a la unificación del derecho de la escuela de derecho público de Pont-à-Mousson sienta las bases de la codificación. En este proceso jugaron un papel clave los juristas J. Bodin y P. Grégoire ${ }^{57}$.

Si el humanismo jurídico del siglo XVI se centró en el derecho y la historia, el humanismo jurídico del siglo XVII, humanismo barroco, tiene además un fuerte componente religioso. Se trata ahora de determinar el derecho de la Iglesia frente al Estado. Nuevamente en este punto el derecho romano proveerá las categorías linguísticas para su elaboración. Grégoire escribe un extenso tratado sobre la materia. Althusius concibe como parte de la política el tema del derecho eclesiástico. Una vez más nos encontramos con la traslación del modelo de Grégoire al pensamiento jurídico alemán. Con todo, el jurista germano publica una obra extensa que constituye una síntesis de derecho romano privado, derecho romano público y política. Para Althusius el derecho alcanza una realización perfecta en la política, concebida esta como una comunicación de bienes ${ }^{58}$. Según Stolleis el humanismo jurídico desarrolló los métodos del "mos italicus" y del "mos gallicus"; el derecho del siglo XVII desarrollará el método del "mos geometricus"59.

Althusius formula este nuevo paradigma político-jurídico en el prefacio de la Política $^{60}$. Este texto puede ser considerado como el programa científico althusiano para el derecho público y la ciencia política. El pensamiento jurídico de Althusius da inicio a lo que la historiografía actual llama Rechtskreiss ${ }^{61}$.

Por un lado, algunos de estos temas se encuentran enunciados y desarrollados en las obras de Bodin y Grégoire. Por otro lado, ellos están presentes y desarrollados parcialmente en los escritos de Althusius. De este modo, el humanismo barroco consolida el proceso político-jurídico iniciado en el siglo XVI por la reforma protestante (Reformation des Rechts) según la tesis recientemente formulada por

\footnotetext{
${ }^{55}$ GréGolre, Pierre, Syntagma iuris universo atque legum pene omnium Gentium et rerumpublicarum praecipuarum (Venetiis, 1593).

${ }^{56}$ Gambino, Luigi, cit. (n. 54): "Col Syntagma il nostro autore mirava alla realizzazione di un progetto ambizioso: chiarire ogni aspetto della realtà giuridica storicamente differenziate, potessero trovarsi e individuarsi come constante punto di riferimento gli universali principi della Giustizia”, p. 14.

${ }^{57}$ Goyard-Fabre, Simone, Philosophie politique XVI-XX siècles (modernité et humanisme) (Paris, PUF, 1987). Señala Goyard-Fabre, p. 168: "Le XVIe siècle avait lui même, en utilisant la leçon des romanistes, apporté un tribut remarquable à ce travail de synthèse: ne citons comme exemples que la Juris universi Distributio de Jean Bodin (1576), le De Republica de Grégoire de Toulouse (1596); mais rappelons l'activité extraordinaire de "l'école doctrinale de droit public de Pont-à-Mousson”.

${ }^{58}$ Carvajal, Patricio, La teoría de los bienes en la Politica de Johannes Althusius como base del pensamiento económico liberal, en REHJ., 27 (2005), pp. 309-327.

${ }^{59}$ STOLLEIS, Michael, cit. (n. 16).

${ }^{60}$ Althusius, Johannes, Politik (1603, traducción alemana y edición crítica de Jansen y Wyduckel, Duncker \& Humblot, Berlin, 2003), pp. 17-22.

${ }^{61}$ Berger, Elizabeth, Deutscher Rechtskreiss, en Europäische Geschichte Online, (ed.). Institut für Europäische Geschichte Mainz, www.ieg-ego.eu/bergere-2010-de
} 
Schmoeckel, la que en definitiva, según señalamos, posibilitará en el siglo XVII la revolución científica en el ámbito específico de la ciencia del derecho.

\section{El pensamiento romano en la obra de Althusius}

La Política althusiana es una síntesis de derecho romano privado y derecho romano público aplicado a la teoría política -Constitución- moderna a partir de la cual se desarrolla un discurso político jurídico específicamente alemán: Reichspublizistik, Staatslehre y Verfassungstheorie. El lenguaje específico de estas disciplinas es el lenguaje de los juristas romanos, pero también de los teólogos de la reforma y de los científicos que participan en la revolución científica moderna.

Como hemos señalado, el derecho romano constituye la disciplina nuclear en J. Althusius, formado en la enseñanza del humanismo jurídico tardío, obteniendo el grado de UJD por la Universidad de Basel. La actividad profesoral de Althusius está vinculada a la Universidad reformada calvinista de Herborn ${ }^{62}$. Con la publicación de la Política (1603) inicia Althusius en Alemania la revolución científica en el ámbito de la ciencia jurídica y de la ciencia política ${ }^{63}$. Aunque permaneció toda su vida profesional vinculado a la academia, su actividad más extensa fue la de síndico en la ciudad portuaria libre hanseática de Emden . Esta experiencia le permitió unir la actividad docente con el ejercicio de la profesión de abogado del comercio. Parte de esa visión pragmática y comprensión de los negocios se manifiesta en la Politica.

Althusius concibió la Política como un manual de derecho público, derecho eclesiástico y ciencia política. En cuanto a la obra romanística específica Althusius escribió una trilogía, a saber: Iuris Romani Libri Duo (1586), Iurisprudentia Romana (1588), Dicaeologica (1617). Según Gierke en la Jurisprudentia Romana Althusius formula el modelo de una sistemática jurídica ${ }^{64}$. Gierke señala además

${ }^{62}$ Carvajal, Patricio, cit. (n. 35).

${ }^{63}$ Carvajal, Patricio; PÉrez, Fernando, La revolución cientifica moderna y su impacto en el pensamiento politico-jurídico alemán del siglo XVII. Johannes Althusius (1563-1638) y Samuel Pufendorf (1634-1694), en Revista de Estudios Politicos, 180 (Madrid, 2018), pp. 105-130.

${ }^{64}$ Gierke, Otto, cit. (n. 14), pp. 37-38 "Nach der Vorrede zu der i.J 1588 erchienenen Ausgabe der "Jurisprudentia Romana" scheint Althusius die Systematisierung des Rechtsstoffs fü eine überhaupt noch nicht gelöste Aufgabe zu halten. Denn er spricht, als wage er den ersten Versuch, und fordert in feierlicher Weise hervorragende Juristen seiner Zeit zur Mitarbeit an einem Werke auf, das weder Ein Mann noch Ein Zeitalter für sich zu vollbringen vermöge. Da er die Schriften der älteren Methodisten (mit Ausnahme des Vigelius) gelegentlich anfürht, betrachtet er dieselben offenbar nicht als systematische Arbeiten in dem von ihm erstrebten Sinn. In der That unterscheiden sich die Systeme seiner Vorgänger von dem seinen durch einen ungleich engeren Anschluss an die Legalordnung. Während die Bestrebungen von Johann Apel (1486-1536) überhaupt mehr auf die dogmatish-dialektische Behandlung der eizelnen Materien, als auf ihre systematische Verbindung giengen, führt Conrad Lagus (1546) zwar als Erster den Gedanken eines systematischen Lehrbuch durch, schliesst sich aber doch in der Hauptsache an die Institutionenordnung an. Eine gleiche Abhängigkeit vom Institutionensystem zeigen die überdies unvollendeten Kommentare des Franciscus Connanus (1508-1551), die zuerst 1552 gedruckt wurden, sowie die zahlreichen methodischen Schriften des Marburger Professors Nicolaus Vigelius (1529-1600) und das Syntagma Juris universi des Petrus Gregorius von Toulouse (1540 bis 1591) vom Jahre 1582. Althusius dagegen legt schon 
que la sistemática civil completa la alcanza Althusius con la Dicaelogica $(1617)^{65}$. El objetivo de Althusius, siguiendo la estructura del derecho romano clásico fue establecer una unión que sintetizara el derecho público con el derecho privado. Este objetivo se alcanza plenamente con la Dicaeologica, una genuina Encyclopedia jurídica del derecho público y derecho civil ${ }^{66}$. Esta última obra del jurista alemán fue un reputado y apreciado manual de estudio en las Universidades europeas de los siglos XVII y XVIII ${ }^{67}$.

En la "Jurisprudentia Romana", "Política” y "Dicaelógica” están desarrollados los temas centrales del derecho romano privado: cosas, personas, propiedad, obligaciones, acciones y delitos, y otros de menor significación como las corporaciones y colegios -consociaciones- pero que en Althusius son la base de una nueva pragmática lingüística político-jurídica que sirve para describir los fundamentos y objetivos de las consociaciones naturales, base de la consociación universal (comunidad, república, Estado). Los discursos de derecho romano de Althusius indicarían lo siguiente: la "Jurisprudentia Romana" fue concebido como un tratado para la docencia, como de hecho se usó en Herborn; la "Dicaeológica" se pensó, en cambio, para la práctica forense, como sucedió en Emden, donde

in der Vorrede zur Jurisprudentia Romana die Mängel des Iusinstitutionensystems in eingehender und treffender Weise dar und führt in dem Buche selbst eine durchaus abweichende Gliederung des Stoffes durch. Sein methodischer Grundgedanke hierbei ist eine rein dialektische Ableitung aller Klassifikationen aus fortschreitender Spaltung der Begriffe. Als die für ihn massgebenden logischen Principien bezeichnet er selbst auf dem Titelblatt die Grunsätze des Petrus Ramus (1515-1572), in welchem man damals den Hauptvertreter einer der Scholastik entgegengesetzten natürlichen Logik verehrte. Die sogenannte Ramistische Methode war freilich schon vorher von andern Juristen auf die einzelnen Materien angewandt.: zum Aufbau eines Systems hat sie Althusius als Erster verwendet. Dem Vorbilde des Alhusius folgte der Marburger Professor Hermann Vultejus (1555-1634), dessen im Jahre 1590 veröffentlichtes Werk nach ganz änhlicher Methode in sachlich abweichender Weise systematisiert ist., während die berúhmten Kommentare des Hugo Donellus (1527-1591) sich wieder näher an das von ihm freilich auf principielle Gesichtspunkte zurückgeführte und im Eizelnen mannifach modificierte Institututionensystem anschlossen".

${ }^{65}$ Ibíd., p. 41: "In der Dicaelogica ist die Systematisierung des Stoffs auf die Spitze getrieben. Von den obersten Grundbegriffen bis in die feinsten Details wird sie mit unerbittlicher Konsequenz, man möchte sagen mit Fanatismus, durchgeführt".

${ }^{66}$ Ibíd., pp. 45-46: "Wie schon diese Uebersicht ergiebt, ist das Werk des Althusius ene Encyklopädie nicht blos des Privatrechts, sondern des geltenden Rechts überhaupt und verdient auch für die Geschichte der strafrechtlichen und processualischen Systematik Beachtung. Von besonderem Interesse aber ist die Art und Weise, in welcher der Verfasser das Staatsrecht in sein System hineingearbeitet hat. Die Aufnahme publicistischer Lehren in das civilrechtliche System ist an sich nichts dem Althusius Eigenthümliches. Wie die gesammte exegetische Literatur seit der Glosse im Anschluss an das Corpus Juris die Erórterung staatsrechtlicher Fragen in den Kreis des Civilrechts gezogen hatte, so hielten die Methodisten an dieser Verbindung fest. Und hierbei versuchten nur Wenige das öffentliche Recht vom Privatrecht als eigenartiges Hauptgebiet zu sondern; regelmässig trug man vielmehr dasselbe innerhalb des privatrechtlichen Rahmens und zwar vorzugsweise im Personenrecht vor".

${ }^{67}$ Ibíd., p. 49: "Hinsichtlich der Begründung und näheren Ausfürung aller von ihm in die Dicaelogica aufgenommenen staatsrechtlichen Sätze verweist Althusius regelmässig aufsein Lehrbuch der Politik. Um so merkwürdiger ist es, dass, während das letztere später so oft als der Flammen werth verdammt wurde, die Dicaelogica unangefochten blieb und selbst noch im 18. Jahrhundert unbefangen zum Rechtsstudium empholen warden kann". 
Althusius fue síndico más de treinta años. Tanto en el texto de la Dicaelógica ${ }^{68}$, como en la Epístola introductoria señala Althusius la necesidad de ordenar las materias que se encuentran dispersas ${ }^{69}$. En este texto se anuncia el programa del Usus modernus pandectarum y, por consiguiente, la codificación racionalista del humanismo jurídico barroco.

\section{Conclusiones}

La Althusiusforschung carece de un estudio sobre la contribución específicamente romanista de Althusius. Sus escritos de derecho romano: "Iurisprudentia Romana", "Dicaelogica” requieren de una edición crítica para fijar el texto canónico.

Los estudios de Wyduckel y Stolleis han matizado la traslación del derecho romano en la formación del discurso político-jurídico de Althusius. Pero la propuesta de P. Laband, a nuestro entender, sigue siendo válida, cuando estudiamos la genética del discurso althusiano y los fundamentos del constitucionalismo y la codificación, según refiere Gierke.

El derecho público de Althusius se nutre del pensamiento romano clásico: San Pablo, Séneca, Cicerón, Digesto; el derecho romano medieval: Bártolo, Baldo, Marsilio de Padua; el derecho romano público del humanismo: J. Bodin, P Gregoire.H. Vultejus. Sobre esta última línea el jurista germano elabora una síntesis de derecho romano público y derecho romano privado, según el modelo de los romanistas italianos medievales, y franceses modernos.

La obras de los juristas romanistas Bodin, Grégoire, Vultejus, Althusius inauguran un nuevo humanismo, el humanismo jurídico barroco, el cual se extiende desde 1560 hasta 1700 . Se puede considerar este humanismo como una expresión de la revolución científica moderna.

La escuela del humanismo barroco es un capítulo en la historia del derecho germano que forma un Rechtskreis. Esta Escuela formula los principios del constitucionalismo, la codificación, el derecho internacional, el derecho natural racionalista, entre otros. Con todo, más del noventa y cinco por ciento de los escritos de esos autores no cuentan con una edición crítica. Este es uno de los grandes desafíos que enfrenta la historiografía político-jurídica-constitucional. Mientras esta situación se mantenga, nuestro conocimiento histórico será deficitario. A modo de ejemplo, la obra de Althusius cuenta solo con ediciones crítica de la Politica.

El derecho romano juega un papel indiscutible en la formación del Estado y de la sociedad europea, desde la Reichspublizistik medieval, base del constitucionalis-

${ }^{68}$ Althusius, Johannes, Dicaelogica (Frankfurt am Main, C. Corvinius, 1649), p. 1: "Totum \& universum Jus, quo utumur, methodice complectentes.... Opus tam theoriae quam praxeos aliarumque Facultatem studiosis utilissimum".

${ }^{69}$ Ibíd., pp. 2-3: "Materiam Juris in libris JCtorum dispersam, ad certa capita \& genera revocavi. A sedibus suis ab aliis turbata \& dimota, in domicilia propia retuli $\&$ in ordinem redegi. Collocavi omnia, meo juicio, eo ordine \& methodo, ut praecedentia lucem sequentibus inserrent, \& sequentia a prioribus lumen acciperent. Vagabuntur \& peregrinabantur quaedam materiae, incertis que sedibus oberrabant, quibusdam eas ad possessionem, vel dominium, quibusdam ad conventiones, quibusdam ad delicta, quibusdam ad judicia eas deposcentibus, quibusdam illis peculiarem \& separatum locum adsignantibus". 
mo moderno, hasta el Usus modernus pandectarum, fundamento de la codificación cuyo resultado es el Code Civil (1804) y el BGB de 1900. La contribución del derecho romano a la cultura europea, se puede resumir con las palabras de tres grandes juristas, a saber: Portalis: "le droit écrit que se compose de lois romaines, a civilisé l'Europe"70; Savygny: "[...] aber kann das Römische Recht, wenn wir es richtig benutzen wollen, die wichtigsten Dienste leisten" "11; en términos actuales, y con un estilo propio del conceptismo barroco, Wiaecker señala: "Et pourtant, le droit romain y fut toujours présent, mais d'une présence cachê"72.

La historia del derecho público moderno alemán según Gierke ${ }^{73}$, Wyduckel ${ }^{74}$, y Stolleis ${ }^{75}$, entendida ahora como historia global de acuerdo con las categorías historiográficas de P. Grossi ${ }^{76}$ y T. Duve ${ }^{77}$, entre otros, nos sitúa en la perspectiva de la traslación global del pensamiento de Althusius. De hecho, el constitucionalismo norteamericano recoge temas esenciales del pensamiento del jurista germano y de la escuela del humanismo barroco.

\section{BiBLIOGRAFÍA}

Antholz, Heinz, Die politische Wirksamkeit des Johannes Althusius in Emden (Ostfriesl, Möckel, 1954).

Aretin, Karl Otmar, Das Alte Reich 1648-1806 (Stuttgart, Klet-Cotta, 1997).

$\mathrm{BACH}$, Oliver, Zwischen Heilsgeschichte und Säkularen Jurisprudenz. Politische Theologie in der Traurespielen des Andreas Grybhins (Berlin, de Gryuter, 2014).

Behrends, Otto; Knüttel, Rolf; Kupisch, Berthold; Hermann Seiler, Hans (eds.), Corpus Iuris Civilis (traducción germana, C.F. Müller Verlag, Heidelberg, 1995, 1997, 1999, 2005).

Berger, Elizabeth, Deutscher Rechtskreiss, en Europäische Geschichte Online (ed.). Institut für Europäische Geschichte Mainz, www.ieg-ego.eu/bergere-2010-de

Bodenheimer, Ulrich, Consonantia Theologiae et Jurisprudentiae. Andreas Bodenstein von Karlstadt als Theologe und Jurist zwischen Scholastik und Reformation (Tübingen, Mohr, 1977).

BRAND, Reinhard (ed.), Rechtsphilosophie der Aufklärung. Symposium Wolfenbüttel (Berlin, de Gruyter, 1982)

${ }^{70}$ Portalis, Jean-Étienne-Marie, Discours préliminaire du premier projet de Code Civil, en: htt://classiques.uqac.ca

${ }^{71}$ SAVIGNY, Friedrich, System des heutigen Römischen Rechts (Berlin, 1840), Band I. Vorrede, p. XXV, en www.deutschestextarchiv.de/book/view/savigny_system01

${ }^{72}$ Wiacker, Franz, Eclipse et permanence du droit romain, en Mesnard, Pierre (dir.), Pédagogues et juristes (Paris, Librairie Philosophique J. Vrin, 1963), p. 68.

${ }^{73}$ GierKe, Otto, cit. (n. 14).

${ }^{74}$ WYDUCKel, Dieter, cit. (n. 15).

${ }^{75}$ STOLLeis, Michael, cit. (n. 16).

${ }^{76}$ Grossi, Paolo, De la codificación a la globalización del derecho (trad. castellana, Editorial Aranzadi, Madrid, 2010).

${ }^{77}$ Duve, Thomas, Global Legal History: Setting Europe in Perspective, en PIHLAjamäKI, Heikki; Dubber, Markus; Godfrey, Mark (eds.), The Oxford Handbook of European Legal History (Oxford University Press, 2018). 
Carvajal, Patricio, La teoría de los bienes en la Politica de Johannes Althusius como base del pensamiento económico liberal, en REHJ., 27 (2005), pp. 309-327.

- La Staatslehre alemana moderna. De Johannes Althusius a Jürgen Habermas. Imperio, Constitución, Estado, y Comunidad Europea. Estudios sobre la Historia constitucional de Alemania, en Obando, Iván; Vergara, Fabiola (eds.), Comunidad, justicia y democracia (Santiago, Librotecnia, 2015), pp. 61-107.

- Los derecho humanos. Una interpretación histórico-filosófica, en Vergara, Fabiola (ed.), Problemas actuales de filosofía jurídica (Santiago, Librotecnia, 2015), pp. 191-231.

-La "Staatslehre" de Johannes Althusius (1557-1638) y la escuela de jurisprudencia de Herborn, en REHJ., 36 (2014), pp. 413-436.

- La historia del derecho y la historiografía jurídica alemana del siglo XX, en REHJ., 32 (2010), pp. 453-468.

-La "Staatslehre" de Henning Arnisaeus (1575-1636) y la "Schule von Helmstedt". Un análisis en conmemoración de los 400 años de la "Politica" (1606-2006), en REHJ., 28 (2006), pp. 551-576.

- La teoría de la Constitución en la "Politica" de Johannes Althusius, en REHJ., 37 (2015), pp. 477-502.

—Breve historia constitucional de Chile (Sociedad Hermann Conring, Valparaíso, 2015).

Carvajal, Patricio; Pérez, Fernando, La revolución cientifica moderna y su impacto en el pensamiento político-jurídico alemán del siglo XVII. Johannes Althusius (1563-1638) y Samuel Pufendorf (1634-1694), en Revista de Estudios Politicos, 180 (Madrid, 2018), pp. 105-130.

Chaunu, Pierre, La civilización de la Europa clásica (1966, traducción castellana, Editorial Juventud, Barcelona, 1976).

CoIng, Helmut, Die Frankfurter Reformation von 1578 und das Gemeine Recht ihrer Zeit (Frankfurt am Main, 1935).

-Die Rezeption des römischen Rechts in Frankfurt am Main. Ein Beitrag zur Rezeptionsgeschichte (Frankfurt am Main, 1939).

-Handbuch der Quellen und Literatur der neueren Europäische Privatrechtsgeschichte (München, Beck, 1996). Bd I; (München, Beck, 1977) Bd. II.

DAнм, Wilhelm-Karl, Johannes Althusius-Ein Rechtsgelehrter als Vordenker der Demokratie, en Dahm, Whelm-Karl; KraWIETz, Werner; Wyduckel, Dieter (eds.), Politische Theorie des Johannes Althusius (Berlin, Duncker \& Humblot, 1987), pp. 21-41.

DÖLEMEYER, Barbara: Rechtsräume, Rechtskreise, en Europäische Geschichte Online (EGO), hg. vom Institut für Europäische Geschichte (IEG), Mainz 2010-12-03. URL: http://www.ieg-ego.eu/doelemeyerb-2010

D'Ors, Álvaro (ed.), El Digesto justineano (Pamplona, Editorial Aranzadi, 19681973), 3 vols.

Dreitzel, Horst, Protestantischer Aristotelismus und Absoluter Staat. Die "Politica" des Henning Arnisaeus (c.1575-1636) (Wiesbaden, franz Steiner Verlag, 1970).

-Absolutismus und ständische Verfassung in Deutschland. Ein Beitrag zu Kontinuität und Diskontinuität der politischen Theorie in der Frühen Neuzeit (Mainz, Philipp von Zabern, 1992).

Ducos, Michèle, Le "Tableau du droit universel" de Jean Bodin et la tradition romaine, en Bulletin de l'Association Guilleume Budé, 1 (1987), pp. 49-61.

DuchHARDT, Heinz, Barock und Aufklärung (Oldenburg, München, 2007). 
Duve, Thomas, Global Legal History. Setting Europe in Perspective, en PinlajamäKI, Heikki; Dubber, Markus; Godfrey, Mark (eds.), The Oxford Handbook of European Legal History (Oxford University Press, 2018).

ERnst, Wolfgang; JАКАB, Eva (eds.), Usus Antiquus Juris Romani / Antikes Recht in lebendespraktischen Anwendung (Berlin, Springer Verlag, 2005).

FernándeZ de Buján, Antonio, Derecho público romano (Madrid, Editorial Civitas, 1996).

FRANKLIN, Julian, Jean Bodin and the sixteenth - century revolution in the methodology of Law and History (New York, Columbia University Press, 1963).

ERnst, Wolfgang; JaKAB, Eva, Usus Antiquus Juris Romani. Antikes Recht in Lebenspraktischer Anwendung (Berlin, Springer Verlag, 2005).

FrankLIn, Julian, Jean Bodin and the Rise of Absolutist Theory (Cambridge University Press, 1973).

FRIEDRICH, Carl Joachim, Johannes Althusius und sein Werk im Rahmen der Entwicklung der Theorie von der Politik (Berlin, Duncker \& Humblot, 1975).

Gambino, Luigi, Il de Republica di Pierre Gregoire. Ordine político e Monarchia nella Francia di fine cinqucento (Roma, Giufrè Editore, 1978).

GENET, Jean-Philippe (dir.), Rome et l'État moderne européen (Rome, 2007).

GIERKE, Otto, Johannes Althusius und die Entwicklung der naturrechtlichen Staatstheorien. Zugleich ein Beitrag zur Geschichte der Rechtssystematik (Scientia Aalen, 1958).

Goyard-Fabre, Simone, Philosophie politique XVI-XX siècle (modernité et humanisme) (Paris, PUF, 1987).

Grossi, Paolo, De la codificación a la globalización del derecho (trad. castellana, Madrid, Editorial Aranzadi, 2010).

GuZMÁn, Alejandro, La Codificación en Iberoamérica (Navarra, Editorial Aranzadi, 2006).

—Ratio Scripta (Frankfurt am Main, Vittorio Klostermann, 1981).

- La fijación del derecho (Valparaíso, Ediciones Universitarias, 1977).

—Derecho romano privado (Santiago, Editorial Jurídica de Chile, 1996), 2 vols.

- La proyección del tratado sobre estipulaciones de los "Libri Tres Iuris Civilis" de Sabino en los "Digestas" de Juliano, y las "Institutiones" de Gayo y el "Corpus Iuris", en REHJ., 30 (2008), pp. 81-98.

Haferkamp, Hans-Peter; Repgen, Tilman (eds.), Usus Modernus Pandectarum. Römisches Recht, Deutches Recht und Naturrecht in der Frühen Neuzeit (Köln, Böhlser Verlag, 2007).

HollenbaCH, Alexander, Jurisprudenz in Freiburg. Beiträge zur Geschichte der Rechtswissenschaftlichen Fakultät der Albert-Ludwigs-Universität (Tübingen, Mohr, 2007).

Hamza, Gabor, Historische Bemerkungen zum Pandektensystem, en Revista Internacional de Derecho Romano (octubre 2013), pp, 150-165.

Hartmann, Peter Claus, Das Heilige Römische Reich deutscher Nation in der Neuzeit 1486-1806 (Stuttgart, Reclam, 2005).

Heckel, Martin, Matin Luthers Reformation und das Recht. Die Entwicklung der Theologie Luthers und ibre Auswirkung auf das Recht unter dem Rahmenbedingungen der Reichsreform und der Territorialstaatsbildung im Kampf mit Rom und den "Schwärmern" (Tübingen, Moehr Siebeck, 2016).

Heger, Martin, Recht im "Alten Reich"- Der Usus modernus, en Zeitschrift für das Juristische Studium, 1 (2010), pp. 29-39, www.zjs-online.com 
Hessler, John, Editing Justinian's Corpus. A Study of the Paul Krueger Archive, en Law Library, 103/3 (2011), pp. 459-472.

KIsCH, Guido, Gestalten und Probleme des Humanismus und Jurisprudenz. Neue Studien und Texte (Berlin, De Gruyter, 1969).

Kunn, Thomas, La estructura de las revoluciones cientificas (1962, trad. castellana, 2a reimp., Fondo de Cultura Económica, Santiago, 1996).

LePsius, Susanne, Ius Commune in der Reichspublizistik der frühen Neuzeit, en DILCHER, Gerhardt; Quaglioni, Diego (eds.), Gli inizo del diritto publico (Bologna, Il Mulino, 2011), pp. 533-562.

Limbach, Jutta, Die kulturellen Werte Europas, en Eckert - Das Bulletin, 12 (Winter, 2012), pp. 12-17.

LORTZ, Joseph, Historia de la Reforma (1962, trad. castellana, Madrid, Taurus Ediciones, 1963), I.

- Historia de la Iglesia en la perspectiva de la historia del pensamiento. Antigüedad y Edad Media (trad. castellana, Ediciones Cristiandad, Madrid, 2003).

MaChiaVElli, Nicolo, Il principe (1534, Einaudi, Torino, 1961).

Malandrino, Corrado (ed.), La Politica elaborata orgánicamente con método, e illustrata con esempli sacrae e profani (Torino, Claudiana, 2009), 2 vols.

Manent, Pierre, An intelectual History of Liberalism (1987, trad. inglesa New Yersey, Princeton University Press, 2005).

MazzaCANe, Aldo, Szienza, lógica e ideología nella giuresprudenza tedesca del secolo XVI (Mailand, 1971).

MencK, Gerhard, Die hohe Schule Herborn in ihrer Frühzeit (Wiesbaden, 1981).

Mussang, Dorothee, Ernst Levy and Wolfgang Kunkl Briechwechsel 1922- 1968 (Heidelberg, Verlag Winter, 2005),

Nilges, Yvonne, Dichterjuristen. Studien zur Poesie des Rechts vom 16. Bis 21. Jahrhundert (Würzburg, Könighauser \& Neumann, 2014).

PORTALIS, Jean-Étienne-Marie, Discours préliminaire du premier projet de Code Civil, en htpp://clasiques.uqac.ca. p. 25

Pufendorf, Samuel, Die Verfassung des deutsches Reiches (1667, Stuttgart, Reclam, 1985).

QuAGLIONI, Diego, I Limiti della sovranità. Il pensiero di Jean Bodin nella cultura política e giuridca dell'età moderna (Padova, Casa Editrice Dott. Antonio Milani, 1992).

Ramis, Rafael, Petrus Ramus y el derecho (Madrid, Universidad Carlos III, 2015).

Rawls, John, Liberalismo politico (1993, trad. castellana, México, Fondo de Cultura Económica, 1996).

Schmoeckel Mathias, Das Recht der Reformation. Die epistemologische Revolution der Wissenschaft und die Spaltung der Rechtsordung in der frühen Neuzeit (Tübingen, Mohr Siebeck, 2014).

SCHNUR, Roman, Die französische Juristen im konfesionellen Bürgerkrieg des 16. Jahrhunderts. Ein Beitrag zur Entstehungsgeschichte des modernen Staates (Berlin, Duncker \& Humblot, 1962).

SCHÖDER, Jan, Die Erneuerung der Rechtswissenschaft im späten 17 Jahrhundert, en FreEdMAnN, Joseph (ed.), Die Zeit um 1670. Eine Wende in der europäischen Geschichte und Kultur, en Wolfenbütteler Forschungen Bd. 142 (Wolfenbüttel Herzog August Bibliothek, 2016), pp.213-230

SCHÖDER, Jan, Methodenlehre, historisch, en Enzyklopädie zu Rechtsphilosophie / en www.enzyklopaedie-rechtsphilosophie.net 
Schokendorff, Eberhard, Theologie der Freiheit (Herder Verlag, Freiburg, 2007).

SCHulze, Reiner, Europäische Rechts- und Verfassungsgeschichte. Ergebnisse und Perspektiven der Forschung (Berlin, Duncker \& Humblot, 1991).

SKINNER, Quentin, The Foundations of modern political thought (Cambridge Universite Press, 1978), 2 vols.

-Liberty before liberalism (Oxford University Press, 1998).

STOLLEIS, Michael (ed.), Juristen. Ein biographisches Lexikon. Von der Antike bis zum 20. Jahrhundert (München, Beck, 2001).

- Staat und Staatsräson in der frühen Neuzeit. Studien zur Geschichte des Öffentlichen Rechts (Frankfurt am Main, Suhrkamp, 1990).

—(ed.), Hermann Conring (1606-1681). Beiträge zu Leben und Werk (Berlin, Duncker \& Humblot, 1983).

—(ed.) Staatsdenker im 17. und 18. Jahrhundert. Reichspublizistik, Politik, Naturrecht (Frankfurt am Main, Metzner Verlag, 1977).

-Öffentlichen Recht in Deutschland. Eine Einführung in seine Geschichte (München, Beck, 2014).

-Recht in Unrecht. Studien zur Rechtsgeschichte des Nationalsozialismus (Frankfurt am Main, Suhrkamp, 2006).

— Geschichte des Öffentlichen Rechts in Deutschland (München, Beck Verlag, 1988), I.

STrauss, Gerald, Law, Resistence, and the State. The opposition to Roman Law in Reformation Germany (New Yersey, Princeton University Press, 1986).

STronm, Christoph (ed.), Späthumanismus und Reformierte Konfession. Theologie, Jurisprudenz und Philosophie in Heidelberg in der Wende zum 17. Jahrhundert (Heidelberg, 2006).

- Calvin und die reformierten Juristen des 17. Jahrhunderts, en HofHeInZ, Marco; Lienemann, Wolfgang; Salmann, Martin (eds.), Calvins Erbe. Beiträge zur Wirkungsgeschichte Jahannes Calvins (Göttingen, Vanderhoeck \& Ruprecht, 2011).

-Ethik im frühen Calvinismus. Humanistische Einflüsse, philosophische, juristische und theologische Argumentationen sowie mentalitätsgeschichtliche Aspekte am Beispiwel des Calvin-Shülers Lambertus Danaeus (Berlin, De Gruyter, 1966).

-Calvinismus und Recht (Tübingen, Mohr \& Siebeck, 2008).

-Konfesionalität und Jurisprudenz in der frühen Neuzeit (Berlin, Duncker \& Humblot, 2009).

Sueur, Philippe, Histoire du droit public francais. XVe - XVIIIe siecle (Paris, Presses Universitaires de France, 1989), 2 vols.

ThiEme, Hans, Die Basñler Doktorthesen des Johannes Althusius. De succesione ab intestato, en Obermayer, Klaus (ed.), Festschrift für Hans Liermann zum 70. Geburstag (1964).

Troje, Hans, Arbeitshypothesen zum Thema "Humanistische Jurisprudenz, en Tijdschrift voor Rechtsgeschiedenis, 38 (1970), pp. 519-563.

Ulbrich, Otto (ed.), Die leidige Seuche.Pest-Fälle in der Frühen Neuzeit (Köln, Böhlau Verlag, 2004).

VIERHAUS, Rudolf, Herrschaftsverträge, Wahlkapitulationen, Fundamentalgsetze (Göttingen, Vandenhoeck \& Ruprecht, 1977).

WeSENER, Gunter, Ius Romano Germanicum - Zur Rechtsquellenlehre des Usus modernus pandectarum, en Fundamina, 20/2 (Pretoria, 2014), pp. 1031-1041. 
Wieacker, Franz, Eclipse et permanence du droit romain, en Mesnard, Pierre, Pédagogues et juristes (Paris, Librairie Philosophique J. Vrin, 1963), pp. 59-72.

Winters, Peter, Die Politik des Johannes Althusius und ihre zeitgenössischen Quellen. Zur Grundlegung der politischen Wissenschaft im 16.und im beginnenden 17.Jahrhundert (Freiburg, Rombach Verlag, 1963).

Wyduckel, Dieter, Princeps Legibus Solutus. Eine Untersuchung zur frühmodernen Rechs- und Staatslehre (Berlin, Duncker \& Humblot, 1979).

- Johannes Althusius, en Grossfeld, Bernhard; PotTMEyer, Ernst; Michel, Klaus; BeCKMAnN, Martin (eds.), Westfälische Jurisprudenz. Beiträge zur deutschen und europäischen Rechstkultur (Münster, Waxmann, 2000), pp. 95-110.

-Ius Publicum. Grundlagen und Entwicklung des Öffentlichen Rechts und der deutschen Staatsrechtswissenschaft (Berlin, Duncker \& Humblot, 1986).

Zasius, Ulrich, Kritik an den Postglossatore, en Wolf, Ernst, Ulrich Zasius. Von wahrer und falsher Jurisprudenz. Aus Schriften, Reden und Briefen 1507 bis 1526 (Frankfurter am Main, Vittorio Klostermann, 1984), p. 7.

ZelLer, Wolfgang, Der Jurist und Humanist. Martin Prenninger gen. Uranius (14501501) (Tübingen, Mohr, 1957).

ZimmERmanN, Reinhardt, Jurists Uproted. German-speaking Emigré Lawyers in TwentiehCentury Britain (Oxford University Press, 2004). 